\title{
Synthesis and Characterization of Encapsulated 1-Tetradecanol for Thermal Energy Storage
}

\author{
K.Vijayrakesh, S.Muthuvel
}

\begin{abstract}
Microencapsulated phase change material (PCM) is used for industrial and house hold air conditioning system for longer term usage. In this study 1-Tetradecanol (C14H30O) is used as a core material. Urea (CH4N2O)-Formaldehyde (CH2O) is used as shell material. Micro capsulation is made using in-situ polymerization technique. Prepared microcapsules were tested for feasibility to use cooling system. The average size was verified using Scanning Electron microscope (SEM) and result was found $3 \mu \mathrm{m}$ and shape was observed as spherical and surface morphology was smooth. The presence of chemicals of core and shell materials was verified by Fourier Transform Infra-Red spectroscopy (FT-IR). The peak temperature of microcapsules was found as $150^{\circ}$ C from Thermo Gravimetric Analyzer (TGA). Thermal cyclic stability was verified by Differential Scanning Calorimetry (DSC). The cyclic temperature was observed as $45.9^{\circ} \mathrm{C}$ and $39.78^{\circ} \mathrm{C}$. These prepared microcapsules can used to control the temperature of $37^{\circ} \mathrm{C}$. This prepared microcapsule can be used for room air conditioning system
\end{abstract}

Keywords :Phase change material, Microencapsulation, 1-Tetradecanol, Urea-Formaldehyde shell, In-situ polymerization

\section{INTRODUCTION}

The present scenario shows that the energy consumption for everyday usage drastically increases due to increasing needs of air conditioning and refrigeration systems. To fulfil the need for energy more power sources are needed, such as atomic power plants, hydel power plants, thermal power plants and renewable power plants which involves huge investment and causes environmental pollution problems. The energy consumption varies across the day which makes the power plants unbalanced. High energy consumption is not only a problem for power plants but also it creates a large amount of emissions. Hence a deep research is required to balance the power requirement and reduce the environmental impact.

Energy utilization is mainly required for room air conditioning system, it is needed from an ordinary fan to till intelligent air-conditioning system. For example, in the food processing industries and pharmaceutical industries to preserve the quality of products a cooling environment required [2]. Hence, the refrigerators are used to fulfill these needs. Nevertheless, transporting the food products and medicines is highly complicated to maintain the same temperature [1]. Therefore the thermal environment of products should be maintained till it reaches the customers to maintain the quality. For transporting the products from one

Revised Manuscript Received on December 20, 2019.

* Correspondence Author

First Author Name*, his/her department, Name of the affiliated College or University/Industry, City, Country. Email: xyz1@blueeyesintlligence.org

Second Author Name, department, Name of the affiliated College or University/Industry, City, Country. Email: xyz2@blueeyesintlligence.org

Third Author Name, department, Name of the affiliated College or University/Industry, City, Country. Email: xyz3@blueeyesintlligence.org to another place, various techniques are in use, such as dry ice cooling, vapor absorption, compression refrigeration, Passive cooling and peltier cooler [2].

To reduce energy utilization, passive cooling is suggested as one among the best options for maintaining the temperature. The passive cooling is also used as thermal latent heat storage for household and industrial usage [3]. In latent heat storage process, many methods are suggested, and the most commonly used methods are, pure phase changing material packs, the phase change material mixing metal particles for high thermal conductivity, form stable phase materials composites and encapsulated phase change materials [5][6][7]. Phase change materials have a disadvantage when heated more than melting temperature for a longer period it will unstable. That is, low heat transfer rate is available when used directly and after the its melts it cannot gain its shape again. If high thermally conductive metal powders is used, the sedimentation problem will be developed, which will reduce multicyclic usage with the same efficiency. Hence the encapsulation method is suggested for better use of PCM for a long period of time. But, to increasing thermal conductivity, the micro encapsulation method is suggested [7]. PCM capsules produced in various sizes such as macro encapsulation, micro encapsulation and nano encapsulation. In macro encapsulation, the surface area is less so heat transfer rate is also low due to less heat absorption, which reduces the efficiency of PCM. So micro encapsulation method is suggested [8].

Selecting a chemical polymerization method for microencapsulate preparation is a vital one, as it is highly chemically sensitive. Several methods were used for microencapsulation together with interfacial polymerization [11], complex coacervation [12] and emulsion polymerization [13][17], in-situ polymerization [14] and suspension polymerization [8][9]. Among several types of polymerization method, in this work, in-situ polymerization was adopted. In situ polymerization is widely used because this encapsulation method gives excellent diffusion tightness [16]. In in-situ polymerization method, microcapsules are formed by making shell material as emulsion and core material mixed in liquid form by heating unto its melting state. Then the emulsion will cover the core material due to the chemical reaction which forms the microcapsules and the size can be varied based on stirring speed and steering time.[12] .

The study conducted by Fang et al.(2009)reported that Tetradecane $\left[\mathrm{C} 14 \mathrm{H} 30\right.$, Melting point $6^{\circ} \mathrm{C}$ and boiling point $257^{\circ} \mathrm{C}$ ] as core material and urea formaldehyde as shell material also in-situ polymerization technique was used and reported that the formation of microcapsules [27]. 
In the present study, 1-Tetradeconal $(\mathrm{C} 14 \mathrm{H} 30 \mathrm{O})$ is used as core material which has a melting point of $37.5^{\circ} \mathrm{C}$ and boiling point of $260^{\circ} \mathrm{C}$ and urea formaldehyde (thermal conductivity $0.433 \mathrm{Nm}-1 \mathrm{~K}$ ) was used as shell material because of high thermal conductivity next to water $(0.599 \mathrm{Nm}-1 \mathrm{oC})$ [24]. This work focused upon synthesizing and characterization of urea-formaldehyde shell microcapsules containing 1-Tetradeconal as PCM for thermal energy storage to check possibilities of using on room air conditioning system. In this feasibility study, size was verified by SEM which is also used to verify the shape of microcapsule and surface morphology. To confirm the chemical present in the microcapsules, FT-IR characterization was carried out. DSC was used to study the heating and cooling cycle. To verify the thermal stability of microcapsule, TGA was used and results are discussed.

\section{EXPERIMENTAL}

\section{A. Materials}

1-Tetradecanol $(\mathrm{C} 14 \mathrm{H} 30 \mathrm{O})$ was used as core material (purity - 95\% from Alfa aesar, England), Urea (CH4N2O $99 \%)$ and formaldehyde ( $\mathrm{CH} 2 \mathrm{O}-37-4 \% \mathrm{w} / \mathrm{v})$ were used as shell material. Ethylene Malic Anhydride (C2H2(CO)2O EMA) was used as an emulsifier for the water-oil emulsion. Sodium hydroxide $(\mathrm{NaOH})$ and concentrated Hydrochloric acid $(\mathrm{HCl})$ is used for $\mathrm{pH}$ maintenance on the emulsion, Resorcinol $(\mathrm{C} 6 \mathrm{H} 4(\mathrm{OH}) 2)$ is used as a cross-linking agent. Fang et al. (2009) reported various weight percentage of resorcinol and concluded that more than 10 percentages will not create any significant mass ratio on the microcapsules. Hence, the optimum weight percentage of 5 percentages is used in this study. Ammonium chloride $(\mathrm{NH} 4 \mathrm{Cl})$ is used as a nucleating agent. Deionized water as laboratory reagent for dilution process was used in this study.

\section{B.Selecting procedure}

Various methods of encapsulation techniques have been already discussed. Hence in this work in-situ polymerization technique is selected, due to diffusion tightness [16]. The direct polymerization of a single monomer is carried out on the particle surface by an in-situ polymerization method.

\section{C.Preparation of emulsion}

EMA solution was prepared for 2.5 weight percentages of 1-Tetradecanol (2.5 Weight \% of PCM), 100ml distilled water and $2.35 \mathrm{gm}$. EMA were added and stirred at $500 \mathrm{rpm}$ in magnetic stirrer until it changes to colorless condition and stored in an airtight test tube.

The following chemicals were added in $200 \mathrm{ml}$ distilled water, materials and its proportions were $0.5 \mathrm{gm}$ resorcinol, $0.5 \mathrm{gm}$ ammonium chloride and $5 \mathrm{gm}$. urea. A $10 \mathrm{ml}$ of prepared EMA solution was taken and added with the above prepared chemical mixture and the mixture was stirred at 500 rpm in a magnetic stirrer until the solution becomes colorless. The $\mathrm{pH}$ level was maintained between 3 and 5 by adding either sodium hydroxide or hydrochloric acid in the droplets based on the requirement the $\mathrm{pH}$ value adjustment.

\section{Theory of microcapsules}

In the prepared emulsion solution, $10 \mathrm{gm}$. of 1-Tetradecanol and $10 \mathrm{gm}$. of formaldehyde were added at $50^{\circ} \mathrm{C}$, after the $\mathrm{pH}$ value adjustment. The stirring operation continued for four hours, maintaining the speed of $1000 \mathrm{rpm}$ to give better surface morphology and smaller particle size [18][19][25]. The temperature of the solution was maintained at $70^{\circ} \mathrm{C}$. Hence, the material will become a solution, for the perfect encapsulation. Subsequent to stirring process, the solution was cooled to room temperature and the solution was filtered using vacuum membrane filter for filtering microcapsules. The process of microcapsule preparation and chemical reactions take place as shown in Eq1.

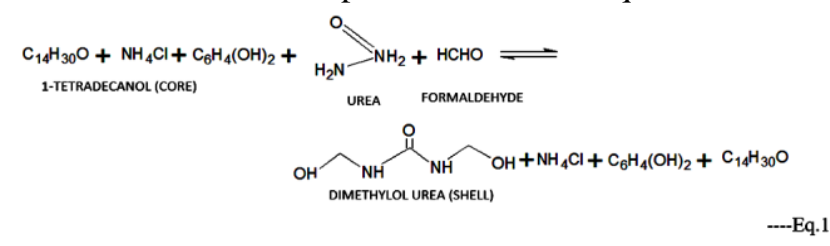

\section{E. Theory of microcapsuleS}

Microcapsules can be verified for various usage parameters, such as size, shape and surface morphology using SEM. For SEM test Scanning Electron Microscope EVO18 (CARL ZEISS), was used. Chemical presents can be verified using FT-IR test and suitable material spectrum can be checked using SHIMADZU-IR TRACER 100 and spectrum observed from 500 to $4000 \mathrm{~cm}-1$ with resolution of $2 \mathrm{~cm}-1$. Then the thermal stability can be verified using TGA 4000 and the instrument type is Pyris 6 TGA. The testing was done with sample mass about $7.568 \mathrm{mg}$ with nitrogen flow of $20 \mathrm{ml}$ / min and initial condition temperature about $30^{\circ} \mathrm{C}$ and the temperature rise programmed as $10^{\circ} \mathrm{C} / \mathrm{min}$. Temperature can be programmed for testing using the above-said instrument from $30^{\circ} \mathrm{C}$ to $500^{\circ} \mathrm{C}$. The phase change properties of 1-Tetrodeconal were estimated by Differential Scanning Calorimetry test (PerkinElmer -Pyris DSC6000).

\section{RESULTS AND DISCUSSION}

\section{A. Scanning Electron Microscope}

It is necessary to find the shape and size of MEPCM, so it is very important to know the surface morphology and there should not be any dimples on the surface [18]. To find the shape, size and surface morphology, SEM was used. Since the surface morphology is considered as an important property for encapsulated phase change materials for better thermal stability on temperature change were also considered for strength. Wei li et al. (2011) investigated n-Octadecane with different copolymer shell materials for the surface morphology of different shell materials and different encapsulation methods and the experiment concluded that the thermal stability depends on surface morphology. Refat AlShannaq et al. (2015) investigated the effect of crosslink agent in microencapsulation strength and concluded that adding crossing linking agent will increase surface morphology and strength[20]. Guruprasad Alva et al.(2017) also reported that the nucleating agent can help to improve surface morphology by adding nucleating agents such as sodium chloride, ammonium chloride for better latent heat stability. In this work, ammonium chloride was used as nucleating agent and resorcinol used as crosslinking agent, Hence the result confirming smooth surface morphology on the microcapsule as shown in Figure. 1a. The Testing of free from buckles and dimples is an important consideration for smooth surface profiles[7], NihalSarier et al.(2007) reported using resorcinol as a cross-linking agent, encapsulation shape obtained as spherical and no dimples found on the surface for 
the same urea-formaldehyde shell[21]. Huanzhi Zhang et al. (2009) also experimented with resorcinol as a cross-linking agent and ammonium chloride as a nucleating agent and reported that the surface morphology is good and shape obtained as sphere for melamine formaldehyde shell[15][22][23]. In this work, shape, size and surface morphology are shown in Figure 1(a), and (b). The experimental preparation shows that the size observed from 1 $\mu \mathrm{m}$ to $6 \mu \mathrm{m}$ and shape of MEPCM is spherical and no dimples were found on the surface. The average size observed from particle distribution on the Figure 1. (c) of MEPCM is $3 \mu \mathrm{m}$. Hence, this result proved that the obtained shape is spherical, surface morphology is smooth without any dimples and average size is $3 \mu \mathrm{m}$.

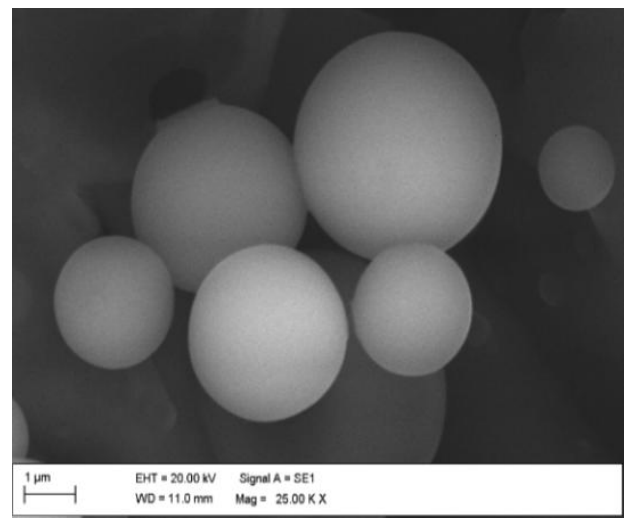

Fig 1(a)

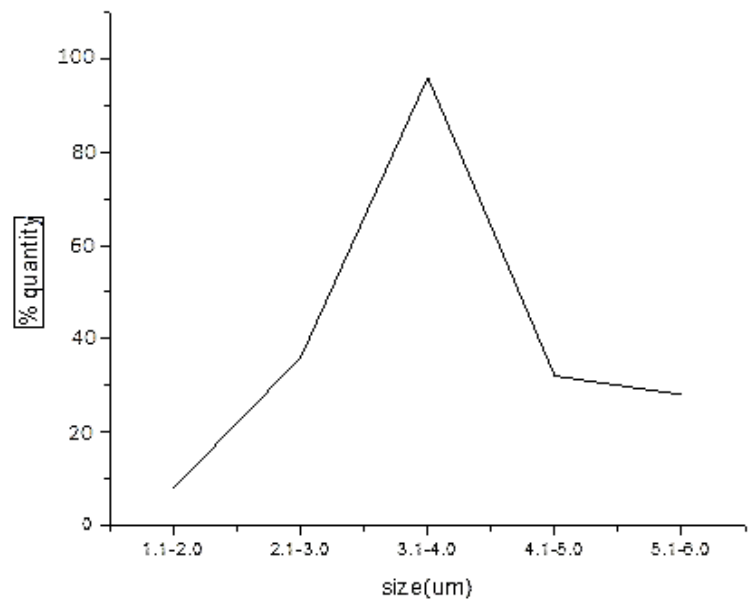

Fig 1(b)

\section{B. Chemical characterization of the microcapsules}

It is necessary to test the presence of shell and core material in the microcapsule. It is verified for the perfect formation of emulsification and encapsulation of phase change material. In this test all the material chemical group individual spectrum analyzed and the result can be verified by comparing the group spectrum on the final encapsulated phase changing material. Similar kind of testing was conducted and reported by various authors. [26], Song et al.2015). Song et al.(2015) also microencapsulated 1-Tetradecanol with poly (methyl methacrylate) used as shell material and found the result for core material. Fang et al. (2009) used Urea-Formaldehyde as shell material and Tetradecane as a core material.

In this study, microcapsules were done by both 1-Tetradecanol and urea-formaldehyde spectrums. The absorption peaks values of 1-Tetradecanol, urea, formaldehyde and the microcapsule are shown in Figure 2. From the FT-IR spectra lines of the microcapsules are available on both the peaks of 1-Tetradecanol and urea and formaldehyde. From Figure 2 it is also observed that the core and microcapsule absorption peaks at $1050 \mathrm{~cm}-1$ to1085 $\mathrm{cm}-1$ is recognized in the stretching vibrations of $\mathrm{C}-\mathrm{O}$ group and the absorption peaks at $718 \mathrm{~cm}-1$ are recognized for stretching vibration in $\mathrm{O}-\mathrm{H}$ group which is the characteristic absorption peaks of 1-tetradecanol.

The absorption peaks of Urea and Microcapsule at 1020 $\mathrm{cm}-1$ to $1250 \mathrm{~cm}-1$ is attributed to stretching vibration in $\mathrm{C}-\mathrm{N}$ group from Figure 2, which is the absorption peaks found for Urea. Similarly, the absorption peaks of Formaldehyde measures from $1685 \mathrm{~cm}-1$ to $1710 \mathrm{~cm}-1$ and available in stretching in $\mathrm{C}=\mathrm{O}$ lines which is the absorption peaks of Formaldehyde which is also shown clearly in Figure 2. This result shows the presence of 1-Tetradecanol, urea and formaldehyde in microcapsules. Hence the above results show the successful formation of microcapsules.

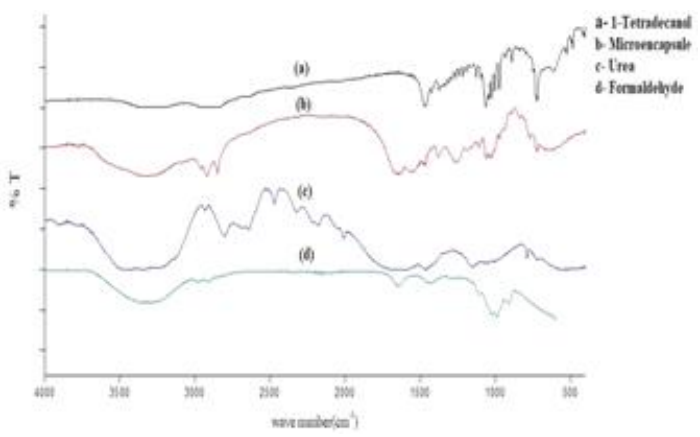

Fig 2. FT-IR (Core,Shell and microcapsule)

\section{Thermogravimetric Analysis}

The efficiency of MEPCM was tested for various thermal environmental conditions of degradation, because the thermally stable encapsulated phase change material can be used under safe temperature range. For this testing, Thermo Gravimetric Analyzer (TGA) is used. In this test, the programmed temperature rose to the sample and compared with the initial mass and changing mass due to evaporation of phase changing material at the temperature difference. Various researchers working on MEPCMs have tested for various temperatures, Song et al.(2015) tested TGA and found encapsulation degradation temperature of 100-175[4]. Fang et al.(2009) also tested with urea-formaldehyde as shell material and found supercooling temperature below $3^{\circ} \mathrm{C}$. In this study, experimental procedure followed as per BS EN ISO 11358:1997 [11]. Figure 3 shows the TGA graph, It is observed that MEPCM starts to degrade from the temperature at $150^{\circ} \mathrm{C}$ and slowly reduced till it reached $170^{\circ} \mathrm{C}$ and significant weight loss started at $170^{\circ} \mathrm{C}$ and then it rapidly decreases its weight at $220^{\circ} \mathrm{C}$ and again it takes slow degradation at $250^{\circ} \mathrm{C}$ till it reaches $300^{\circ} \mathrm{C}$. The weight loss shows less than 10 percentage. Figure 3 clearly shows that significant degradation temperatures are available between $150^{\circ} \mathrm{C}$ and $220^{\circ} \mathrm{C}$. The result has been also shown in Table 1. Hence, The TGA result shows that the thermal stability of microcapsule of 1-tetradecanol as core material and urea-formaldehyde as shell material is good. 


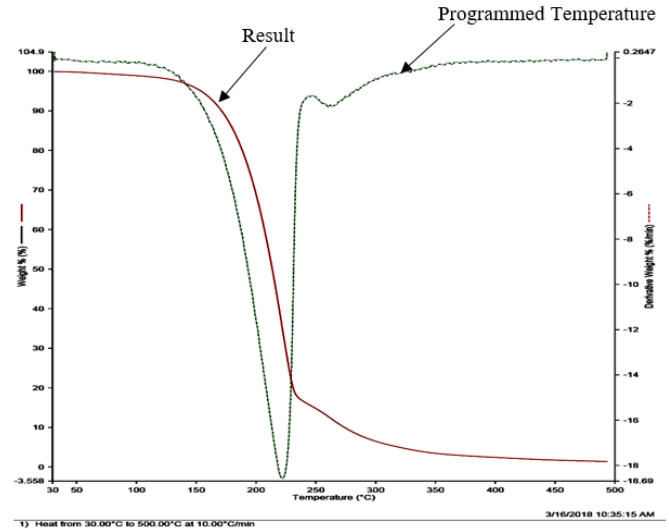

Fig 3 TGA graph

Table-I Comparison of Tetradecanol and Microcapsule

\begin{tabular}{|l|l|l|}
\hline & $\begin{array}{l}\text { Degradation } \\
\text { Temperature }\end{array}$ & Mass loss \\
\hline 1-Tetradecanol & $>100$ & $100 \%$ \\
\hline Microcapsules & $100-150^{\circ} \mathrm{C}$ & $3 \%$ \\
& $150^{\circ} \mathrm{C}-220^{\circ} \mathrm{C}$ & $70 \%$ \\
\hline
\end{tabular}

\section{B.Differential Scanning Calorimetry}

The heating and cooling behavior of microcapsules is studied for better cyclic usage. For finding heating cooling or supercooling, Differential Scanning Calorimetry (DSC) is used for understanding the better usability of their MEPCM at various control temperatures. In this test, the given specimen heated and cooled in programmed temperature will increase and decrease.

In Figure $4 \mathrm{DSC}$ curves show that at $45.9^{\circ} \mathrm{C}$ it shifted from $39.78^{\circ} \mathrm{C}$ for heating and cooling when encapsulation was made and the same peak and reduction obtained in heat flow in the MEPCM. It was also verified from JianguoZuo et al.(2011) for 1-Tetradecanol as pure phase changing material. Similarly, Song et al. (2015) reported for pure 1-Tetradecanol found to be heating and cooling latent heats are $210 \mathrm{~J} / \mathrm{g}$ and $207 \mathrm{~J} / \mathrm{g}$ but when poly(methyl methacrylate) microcapsules 1 -Tetradecanol may $120.7 \mathrm{~J} / \mathrm{g}$ and $118.4 \mathrm{~J} / \mathrm{g}$. Fang et al.(2009) also reported microcapsule using urea-formaldehyde as shell material for Tetradecane as the core material, supercooling temperatures was found at $3.29^{\circ} \mathrm{C}$ for pure tetradecane and $3^{\circ} \mathrm{C}$ for nanocapsules. So this experimental study shows that heating and cooling cycles of microcapsules with 1-tetradecanol as core material and urea-formaldehyde as shell material have better therrmal stability at various controlled temperature.

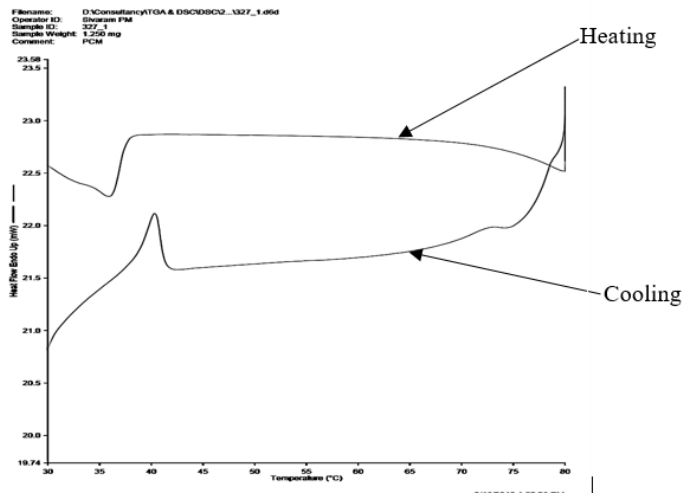

Fig. 4 DSC curve of MEPCM

\section{CONCLUSION}

1-Tetradecanol phase changing material successfully microencapsulated using urea-formaldehyde as shell material with proper control of speed at $1000 \mathrm{rpm}$. The average size of microcapsules was found at $3 \mu \mathrm{m}$ and the surface morphology also conformed as smooth. The particle shape may be found as sphere. Materials for 1-Tetradecanol core and Urea-formaldehyde shell presents conformed using FT-IR by analyzing presents of individual spectrums of materials with spectrum of microcapsules. Thermal peak stability of microcapsules was tested and verified using TGA and the results found that the highest possible temperature of usage is about $150^{\circ} \mathrm{C}$. Thermal cyclic change temperature stability verified was using DSC tests and found $45.9^{\circ} \mathrm{C}$ and $39.78^{\circ} \mathrm{C}$ for heating and cooling. Based on the results found from the study, the microcapsules formed successfully and it can be used for comfortable air conditioning system using heat thermal storage applications.

\section{REFERENCES}

1. Tassou S.A, De-Lille .G, Ge. Y.T., Food transport refrigeration Approaches to reduce energy consumption and environmental impacts of road transport, Applied Thermal Engineering 29 (2009) 1467-1477. https://doi.org/10.1016/j.

2. Arora.C, Refrigeration and Air Conditioning, McGraw Hill Education, 19803 edition, ISBN-13: 978-0070083905,

3. Lane, G. A.; Glew, D. N.; Clarke, E. C.; Quigley, S. W.; Rossow, H. E. Solar energy subsystems employing isothermal heat storage materials, phase 1, Energy Production and Conversion, Technical Report, 18 Sep. 1974 - 30 Apr. 1975. Solar Energy Utilization Pages 451-489, https://doi.org/10.1007/978-94-009-3631-7_22

4. Song Qingwen, Li Yi, Xing Jianwei, Hu J.Y, Marcus Yuen, Thermal stability of composite phase change material microcapsules incorporated with silver nano-particles, Polymer, Volume 48, Issue 11 , 21 May 2007, Pages 3317-3323. https://doi.org/10.1016/j.polymer.2007.03.045

5. Ahmet Sari, Form-stable paraffin/high density polyethylene composites as solid-liquid phase change material for thermal energy storage, Energy Conversion and Management Volume 45, Issues 13-14, August 2004, Pages 2033-2042. https://doi.org/10.1016/j.enconman.2003.10.022,

6. Hawlader. M.N.A., Uddin. M.S., MyaMyaKhin, Microencapsulated PCM thermal-energy storage system,Applied Energy Volume 74, Issues 1-2, January-February 2003, Pages 195-202 https://doi.org/10.1016/S0306-2619(02)00146-0.

7. Alva Guruprasad, Lin Yaxue, Liu Lingkun, Fang Guiyin, Synthesis, characterization and applications of microencapsulated phase change materials in thermal energy storage: A review, Energy and Buildings Volume 144, 1 June 2017, Pages 276-294. https://doi.org/10.1016/j.enbuild.2017.03.063.

8. Weiguang Su, Jo Darkwa, GeorgiousKokogiannakis, Tongyu Zhou, Yiling Yu, Preparation of microencapsulated phase change materials (MEPCM)for thermal energy storage, Energy Procedia Volume 121, September 2017, Pages 95-101. https://doi.org/10.1016/j.egypro.2017.07.485.

9. Luz Sanchez-Silva, Juan F. Rodriguez, AmayaRomero, Ana M. Borreguero, Manuel Carmona, Paula Sanchez, Microencapsulation of PCMs with a styrene-methyl methacrylate copolymer shell by suspension-like polymerization, Chemical Engineering Volume 157, Issue 1, 15 February 2010, Pages 216-222. https://doi.org/10.1016/j.cej.2009.12.013.

10. CemilAlkan, AhmetSarı, AliKaraipekli, OrhanUzun, Preparation, characterizationand thermal properties of microencapsulated phase change material for thermal energy storage, Solar Energy Materials \& Solar Cells Volume 93, Issue 1, January 2009, Pages 143-147,https://doi.org/10.1016/j.solmat.2008.09.009.

11. RezaeeShirin-Abadi A, MahdavianA R, Khoee S, Newapproach for the elucidation of PCM nanocapsules through miniemulsionpoly-merization with an acrylic shell. Macromolecules 2011, 44 (18), pp 7405-7414., DOI: $10.1021 / \mathrm{ma} 201509 \mathrm{~d}$.

12. A.Jamekhorshid, S.M.Sadramelia, M.Farid, A 
review of microencapsulation methods of phase change materials (PCMs) as a thermal energy storage (TES) medium, Renewable and Sustainable Energy Reviews Volume 31, March 2014, Pages 531-542. https://doi.org/10.1016/j.rser.2013.12.033.

13. Song. X. Q, Preparation and Characterization of Tetradecanol Microcapsule Phase Change Materials by Emulsion Polymerization, Advanced Materials Research, Vol. 1089, pp. 137-141, 2015. https://doi.org/10.4028/www.scientific.net/AMR.1089.137

14. FallahiElham, Barmarand Mohammad, Haghighat Mohammad, Kish, Preparation of Phase-change Material Microcapsules with Paraffin or Camel Fat Cores: Application to Fabrics, Iranian Polymer Journal 19 (4), 2010, 277-286, Page(s) 277 To 286.

15. Su JF, Wang SB, Zhang YY, Huang Z (2011) Physicochemical properties and mechanical characters of methanol-modified melamine-formaldehyde (MMF) shell micro PCMs containing paraffin. Colloid and Polymer Science, January 2011, Volume 289 , Issue 2, Pages 111-119, https://doi.org/10.1007/s00396-010-2328-1

16. Zhao. C.Y., Zhang. G.H., Review on microencapsulated phase change materials (MEPCMs): Fabrication, characterization and applications, Renewable and Sustainable Energy Reviews, Volume 15 Issue 8, October 2011, Pages 3813-3832. https://doi.org/10.1016/j.rser.2011.07.019,

17. Seo Park Jun, Ruckenstein Eli, Encapsulation of solid particles by the concentrated emulsion polymerization method, Polymer, Volume 31 , Issue 1, January 1990, Pages 175-179. https://doi.org/10.1016/0032-3861(90)90371-5.

18. Li Wei, Song Guolin, Tang Guoyi, Chu Xiaodong, Ma Sude, Liu Caifeng, Morphology, structure and thermal stability of microencapsulated phase change material with copolymer shell, Energy, Volume 36, Issue 2, February 2011, Pages 785-791, https://doi.org/10.1016/j.energy.2010.12.041.

19. JianguoZuo, Weizhong Li, LindongWeng, Thermal properties of lauric acid/1-Tetradecanol binary system for energy storage. , Applied Thermal Engineering, Volume 31, Issues 6-7, May 2011, Pages 1352-1355, https://doi.org/10.1016/j.applthermaleng.2011.01.008.

20. Al-ShannaqRefat, Farid Mohammed, Al-MuhtasebShaheen, Kurdi Jamal, Emulsion stability and cross-linking of PMMA microcapsules containing phase change materials, , Solar Energy Materials and Solar Cells, Volume 132, January 2015, Pages 311-318. https://doi.org/10.1016/j.solmat.2014.08.036.

21. SarierNihal, OnderEmel, The manufacture of microencapsulated phase change materials suitable for the design of thermally enhanced fabrics, , ThermochimicaActa, Volume 452, Issue 2, 15 January 2007, Pages 149-160. https://doi.org/10.1016/j.tca.2006.08.002

22. Zhang Huanzhi, Wang Xiaodong, Fabrication and performances of microencapsulated phase change materials based on n-octadecane core and resorcinol-modified melamine-formaldehyde shell, , Colloids and Surfaces A: Physicochemical and Engineering Aspects, Volume 332, Issues 2-3, 15 January 2009, Pages 129-138, https://doi.org/10.1016/j.colsurfa.2008.09.013

23. AlperAydinAhmet, OkutanHasancan, High-chain fatty acid esters of myristyl alcohol with even carbon number: Novel organic phase change materials for thermal energy storage-1, Solar Energy Materials and Solar Cells, Volume 95, Issue 10, October 2011, Pages 2752-2762, https://doi.org/10.1016/j.solmat.2011.04.015

24. Wang Xichun, NiuJianlei, Li Yi, Wang Xin ,Chen Binjiao, ZengRuolang, Song Qingwen, Zhang Yinping, Flow and heat transfer behaviors of phase change material slurries in a horizontal circular tube, International Journal of Heat and Mass Transfer, Volume 50, Issues 13-14, July 2007, Pages 2480-2491, https://doi.org/10.1016/j.ijheatmasstransfer.2006.12.024.

25. Behzadnasab. M, Esfandeh. M, Mirabedini. S.M., M.J. Zohuriaan-Mehr, R.R, Farnood, Preparation and characterization of linseed oil-filled urea-formaldehyde microcapsules and their effect on mechanical properties of an epoxy-based coating, , Colloids and Surfaces A: Physicochemical and Engineering Aspects, Volume 457, 5 September 2014, Pages 16-26. https://doi.org/10.1016/j.colsurfa.2014.05.033

26. Fang Guiyin, Li Hui, Yang Fan, Liu Xu, Wu Shuangmao, Preparation and characterization of nano-encapsulated n-tetradecane as phase change material for thermal energy storage, Chemical Engineering Journal Volume 153, Issues 1-3, 1 November 2009, Pages 217-221. https://doi.org/10.1016/j.cej.2009.06.019.

27. E. N. Brown, M. R. Kessler, N. R. Sottos, R. White, In situ poly(urea-formaldehyde) microencapsulation of dicyclopentadiene, Journal of Microencapuslation November, December, 2003, Volume 2003, NO. 6, Pages 719-730. https://doi.org/10.3109/02652040309178083.

\section{AUTHORS PROFILE}

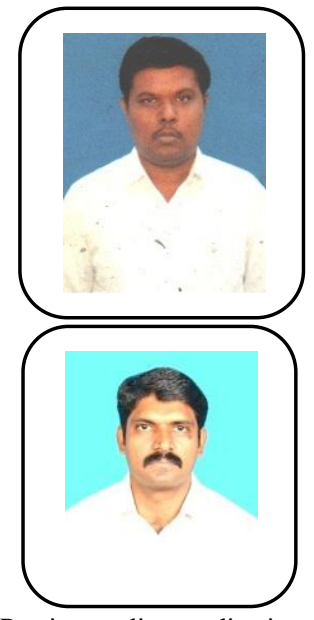

Passive cooling applications.
K.Vijayrakesh, graduated from the Anna University in the year 2009 with Bachelor of Engineering (Mechatronics Engineering) and Masters (Thermal) from Anna University in the year 2013. He has industrial experience in automation at Access automation pvt.ltd.

Dr.S.Muthuvel graduated from the Madurai Kamarajor University in the year 2000 with Bachelor of Engineering (Mechanical Engineering) and Masters from National Insititute of Technology in the year 2005. He has four years of industrial experience in Tata consultancy engineering. He was member of ISTE. His expertise is thermal engineering and 